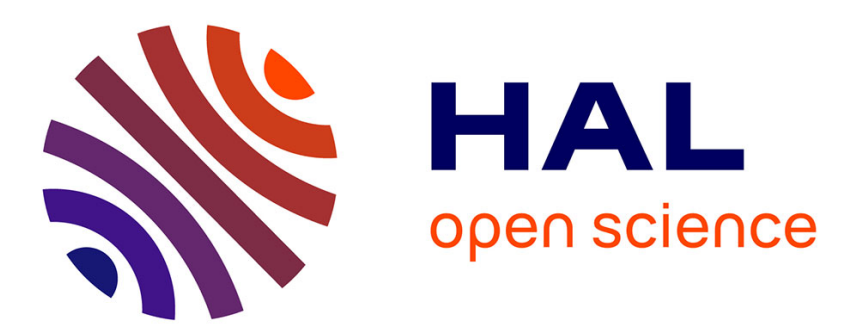

\title{
Influence of design and process parameters on service life of nut hot forging die
}

\author{
Véronique Garat, Gérard Bernhart, Laurence Hervy
}

\section{To cite this version:}

Véronique Garat, Gérard Bernhart, Laurence Hervy. Influence of design and process parameters on service life of nut hot forging die. Journal of Materials Processing Technology, 2004, 147 (3), p.359-369. 10.1016/j.jmatprotec.2003.01.002 . hal-01851438

\section{HAL Id: hal-01851438 \\ https://hal.science/hal-01851438}

Submitted on 11 Jan 2019

HAL is a multi-disciplinary open access archive for the deposit and dissemination of scientific research documents, whether they are published or not. The documents may come from teaching and research institutions in France or abroad, or from public or private research centers.
L'archive ouverte pluridisciplinaire HAL, est destinée au dépôt et à la diffusion de documents scientifiques de niveau recherche, publiés ou non, émanant des établissements d'enseignement et de recherche français ou étrangers, des laboratoires publics ou privés. 


\title{
Influence of design and process parameters on service life of nut hot forging die
}

\author{
Véronique Garat ${ }^{\mathrm{a}}$, Gérard Bernhart ${ }^{\mathrm{a}, *}$, Laurence Hervy $^{\mathrm{b}}$ \\ ${ }^{\text {a E} E c o l e ~ d e s ~ M i n e s ~ d ' A l b i-C a r m a u x, ~ R e s e a r c h ~ C e n t e r ~ o n ~ T o o l s, ~ M a t e r i a l s ~ a n d ~ P r o c e s s e s ~(C R O M e P), ~ 81013 ~ A l b i ~ C T ~ C e d e x ~ 09, ~ F r a n c e ~}$ \\ b LISI Aerospace, BP 298, 12200 Villefranche de Rouergue, France
}

\begin{abstract}
A nut hot forging die was investigated in order to increase its life time. In a first step forging process simulation shows that die surface temperature reaches $450^{\circ} \mathrm{C}$ and that mechanical loads on the die are closely related to the accuracy of the initial billet length. In a second step die thermo-mechanical simulation was used to optimize the design: geometrical aspect as well as shrink fitting were investigated. Life time increase was estimated in using the Manson universal slope relation. This increase was confirmed from the practical results.
\end{abstract}

Keywords: Nut hot forging; Die design; Numerical simulation; Shrink fitting

\section{Introduction}

An aircraft like the airbus A340 is made up of 4 million parts, 2 million of which are fasteners. At the beginning of fastener production, the hot forging step gives the general shape to the product and the hexagonal head is net shape forged. An important aim of the suppliers, nowadays, is to reduce the general costs of their products. The reduction of the costs of the tooling or an increase of their service life contributes to this goal.

Tool scrapping can be attributed to two major causes: the first one is due to wear and loss of accurate dimensions, the second one is rupture after crack propagation. A lot of work has been carried out on this subject for cold forming [1], hot forging $[2,3]$ and the contribution of FEM simulation is clearly demonstrated. Nevertheless, each industrial case is different and requires a specific study.

In this paper, the brittle failure phenomenon of tools is addressed and the influence of process parameters like billet length, billet initial temperature or tool design (radius corner value and shrink fit) are studied. After a description of the industrial tool working conditions, numerical simulation is used to quantify the stress distribution in the tools. The service lives of different designs were estimated using the

\footnotetext{
* Corresponding author. Tel.: +33-5-63-49-30-56; fax: +33-5-63-49-30-99.

E-mail address: bernhart@enstimac.fr (G. Bernhart).
}

universal slope method and some design changes are recommended.

\section{Hot forging tool: presentation of the industrial problem}

In general materials for aeronautical fastener production are very difficult to forge. To withstand the high loads without deformation, high speed steels (HSS) are usually selected. Such materials show low ductility, even at high temperature. This study concerns a hexagonal nut die which shows a very limited service life (often less than 100 pieces are forged before complete failure). While all parameters related to the forging press are closely controlled, other causes such as design, shrink fit influence, temperature or small variations of billet length are assessed.

\subsection{Tools and materials for hexagonal nut hot forging}

The high hardness (61-62 HRc) high speed steel (HS-6-5-2, AISI M2) forging die, described in Fig. 1, is shrink fitted before use in an AISI H11 ring with a $200 \mathrm{MPa}$ loading. The cylindrical billets $(13 \mathrm{~mm}$ long and $7.3 \mathrm{~mm}$ in diameter) are in stainless steel X6 NiCrTiMoV 25. They are lubricated with $\mathrm{MoS}_{2}$ powder, then heated by induction to $1100{ }^{\circ} \mathrm{C}$ and forged with a $25 \mathrm{t}$ press. The forging takes less than $0.1 \mathrm{~s}$ but the time between the strike and the nut ejection is about $8 \mathrm{~s}$, which allows the shrinking of the steel and limits die wear. 


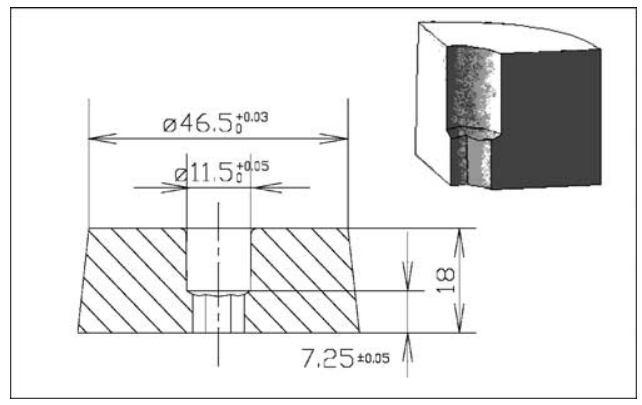

Fig. 1. Dimensions of the hexagonal die.

\subsection{Die failure}

After less than 100 forging cycles, cracks appear in the die corners and reach the external part of the tool a few strikes later, as shown in Figs. 2 and 3. Die failure may be attributed to one of the four following factors [4]:

1. tool steel selection and quality;

2. die design and manufacturing;

3 . heat and surface treatments;

4. forging process parameters.

As points 1 and 3 are supposed to follow the basic rules of the forging industry, this study is focused on the influence of die design and process parameters. To avoid influence of the brittle and heat affected layers due to electro discharge machining (which is known to reduce fatigue life
$[5,6])$, conventional machining was chosen to manufacture the die.

Amongst the possible mechanisms listed by Bobke and Luig [7], i.e. wear, plastic strain, thermal cracking and mechanical cracking, nut forging die rupture is clearly a result of the last one. As a consequence, major effort is placed on the understanding and the explanation of this rupture mechanism in relation to die design and forging process parameters.

\subsection{Design of hexagonal nuts and screws: norms analysis}

Usually, customer specifications give no requirements on the radii in the corners of hexagonal as forged screws and nuts. According to international norms ISO 4759 I and II [8] regarding tolerances on the dimensions of such products, the maximum value allowed for the radius corner can be defined as (Fig. 4):

$$
R_{\mathrm{c}}=\frac{f_{\max }-\sqrt{3} / 2 c_{\max }}{2-\sqrt{3}}
$$

where $R_{\mathrm{c}}$ is the radius corner value, $f_{\max }$ and $c_{\max }$ are the across flat and the across corner dimensions.

Related to the nut geometry, a maximum radius value of $0.6 \mathrm{~mm}$ is allowed. Taking into account a possible non-uniform filling of the die during the forging and a change of dimension due to wear, a maximum allowable radius of $0.5 \mathrm{~mm}$ is considered.

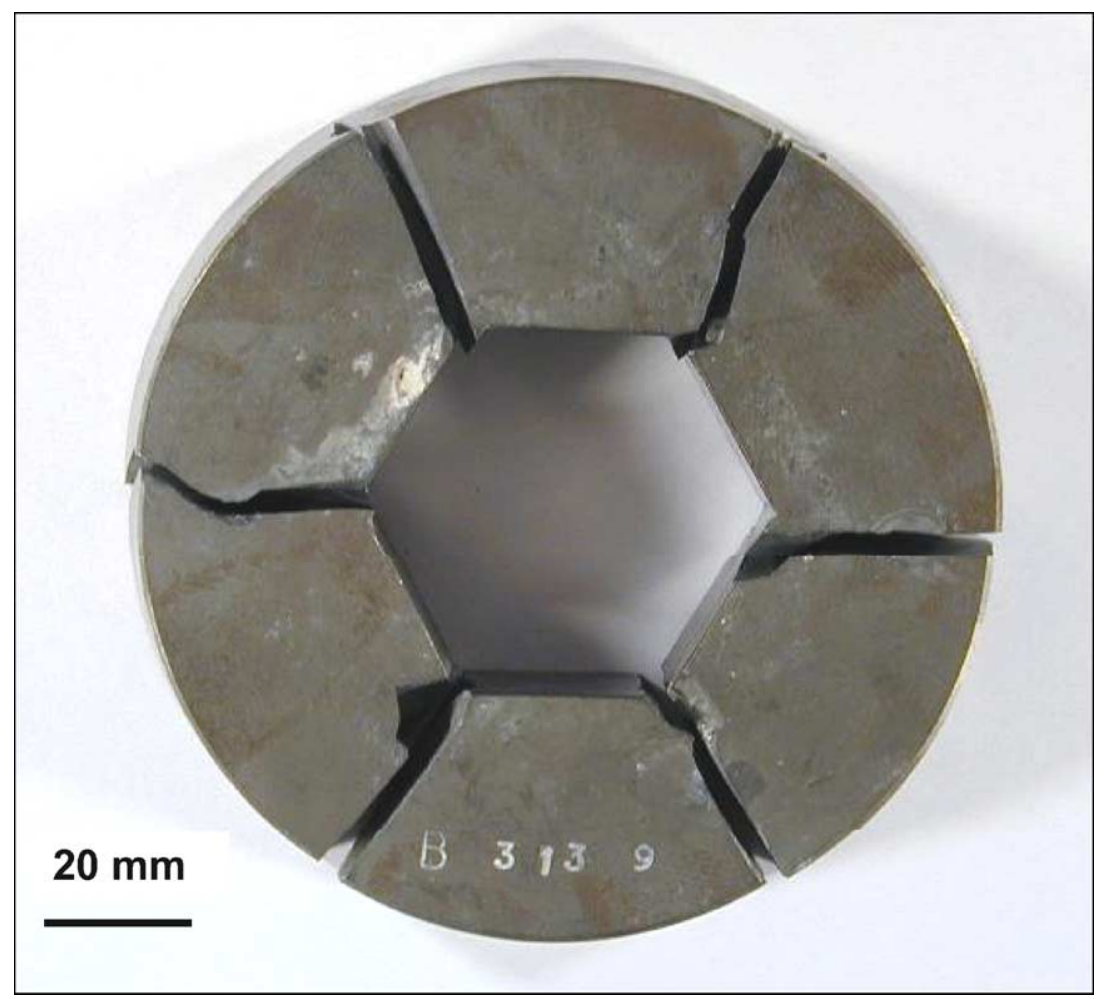

Fig. 2. Typical failure of an hexagonal die at corners. 


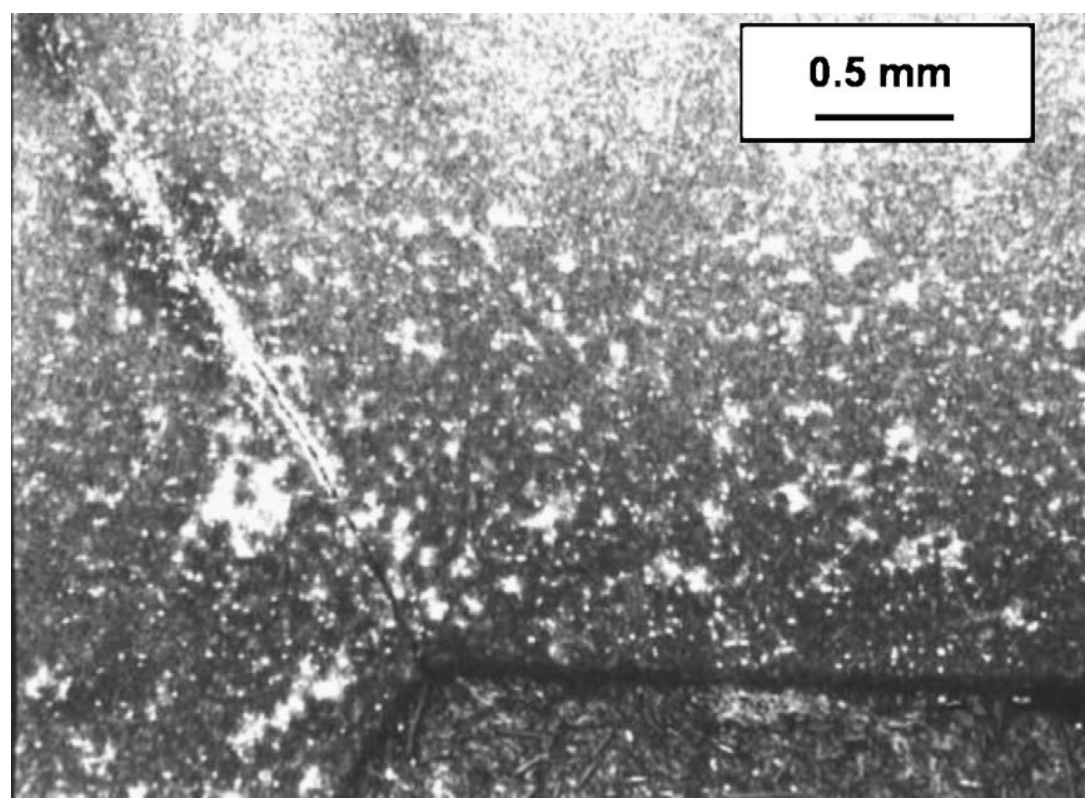

Fig. 3. Failure initiation located in corners.

\section{Numerical simulation of nut hot forging}

\subsection{Presentation of the parametrical study}

The methodological approach followed in this study is shown in Fig. 5. It involves three different steps:

1. the first step consists in the axisymmetric simulation of the forging operation using the FE software Forge $2^{\circledR}$. Two combinations of parameters are studied:

- the initial length of the billet, which is cut from bars and may vary in a range of $\pm 1.5 \%$;

- the initial billet temperature, which is nominally $1100{ }^{\circ} \mathrm{C}$ but can be less (as low as to $1000^{\circ} \mathrm{C}$ ) due to the time required for the billet transfer from the inductor to the die;

2. the second step aims to study the influence of the radius corner value and the shrink fit pre-loading on the stress and strain levels. The non-axisymmetric isothermal simulation is performed using I-DEAS ${ }^{\circledR}$ finite element software;

3. in the third step, the two previous simulations are linked, so that the radial stresses calculated under Forge $2^{\circledR}$ are applied to the different die designs. Results allow an estimation of the service life, thanks to the universal slope method.

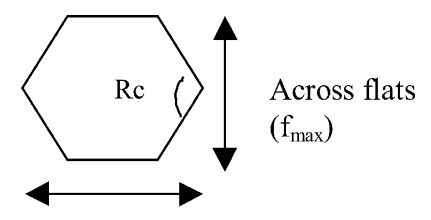

Across corners $\left(\mathrm{c}_{\max }\right)$

Fig. 4. Hexagonal screw, dimensions and radius.
Finally, the optimum parameters (especially, the radius corner value) are tested on the process line to validate the theoretical results.

\subsection{Numerical simulation of forging process parameters variations}

To reduce the computational costs and time, the simulation assumes an axisymmetric die and nut. Fig. 6 shows the evolutive six-node finite element meshing. In order to obtain accurate stress distribution, a refined meshing is used at the inner surface of the die to include the rapid temperature change.

The billet is thermo-viscoplastic, the die is thermo-elastic, the punch and the plate support are assumed to be rigid

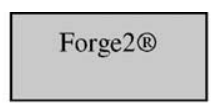

Billet at $1100^{\circ} \mathrm{C}-13 \mathrm{~mm}$ long Billet at $1000^{\circ} \mathrm{C}-13 \mathrm{~mm}$ long Billet at $1100^{\circ} \mathrm{C}-13.2 \mathrm{~mm}$

long $(+1.5 \%$ length $)$

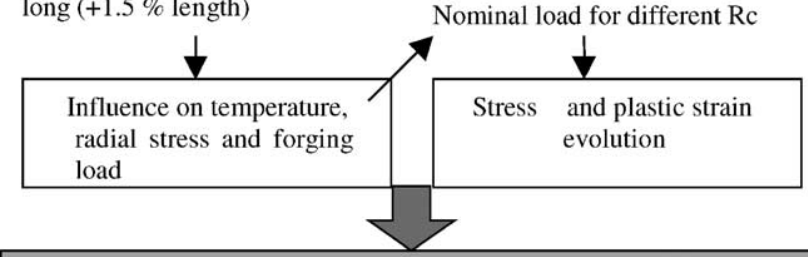
Increasing number of cycles to failure

Control of process parameters
New design for dies - Test of new Rc on production tools
Fig. 5. Methodological approach. 


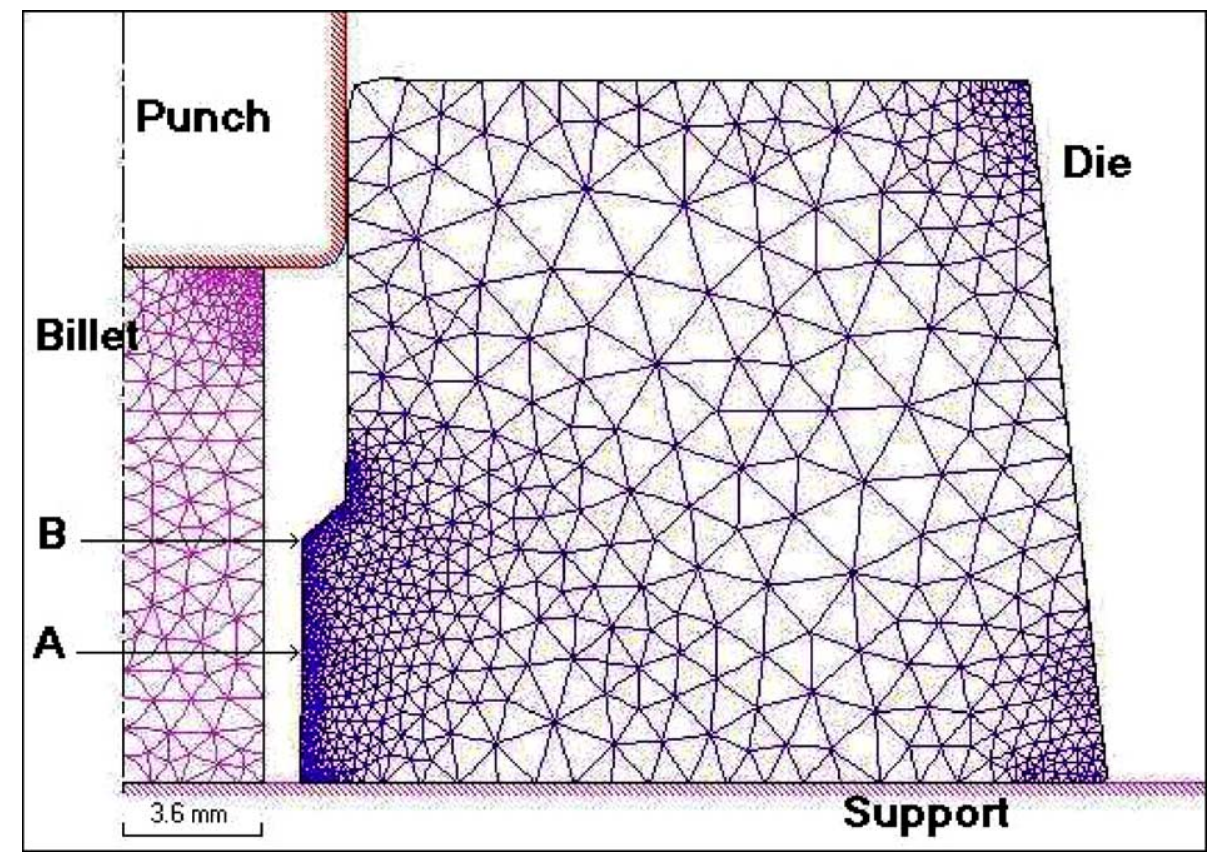

Fig. 6. Mesh of die and billet (Forge $2^{\circledR}$ ).

Table 1

Physical and mechanical properties of HSS M2 steel $[7,8]$

\begin{tabular}{llllllll}
\hline & $E_{0}(\mathrm{GPa})$ & $R_{0.2}(\mathrm{MPa})$ & $\nu_{0}$ & $a_{0}\left({ }^{\circ} \mathrm{C}^{-1}\right)$ & $C_{p}(\mathrm{~J} / \mathrm{kg} \mathrm{K})$ & $\rho\left(\mathrm{kg} / \mathrm{cm}^{3}\right)$ & $\lambda\left(\mathrm{W} / \mathrm{m} \mathrm{K}^{3}\right.$ \\
\hline $20^{\circ} \mathrm{C}$ & 211 & 2155 & 0.31 & 0.378 & 439 & 8.15 & 20 \\
$450^{\circ} \mathrm{C}$ & 180 & 1700 & & & & & \\
\hline
\end{tabular}

bodies. The stress levels along the vertical location of the die are monitored and two points A and B (Fig. 6) are closely observed. Point B corresponds to the transition between the hexagonal head and the flange of the nut (see also Fig. 8).

\subsubsection{Thermal mechanical behavior}

The linear temperature-dependent behavior of the die is described as follows:

$E=E_{0}\left(1+a_{0} T\right), \quad v=v_{0}\left(1+a_{0} T\right)$

with $E_{0}$ the young modulus at $T=20^{\circ} \mathrm{C}$ and $\nu_{0}$ Poisson's ratio at $T=20^{\circ} \mathrm{C}$. Table $1[9,10]$ summarizes the mechanical data.

Billet behavior is described with a Norton-Hoff law, given by Eq. (3):

$\sigma=K_{1} \bar{\varepsilon}^{n} \dot{\bar{\varepsilon}}^{m} \exp \left(\frac{\beta}{T}\right)$

where $K_{1}$ is the consistency, $m$ the strain rate exponent, $\bar{\varepsilon}$ the effective strain, $\dot{\bar{\varepsilon}}$ the effective strain rate and $n$ is the hardening coefficient.
By introducing the stress deviator (Eq. (4)), the constitutive equation used in Forge $2^{\circledR}$ can be derived (Eq. (5)):

$\overline{\bar{s}}=2 K(\sqrt{3} \dot{\bar{\varepsilon}})^{m-1} \overline{\bar{\varepsilon}}$

$K=K_{0}\left(\bar{\varepsilon}+\bar{\varepsilon}_{0}\right)^{n} \exp \left(\frac{\beta}{T}\right)$

with $K_{0}=K_{1} /(\sqrt{3})^{m+1}$ and $\dot{\bar{\varepsilon}}=\sqrt{(2 / \sqrt{3}) \overline{\bar{\varepsilon}}: \overline{\bar{\varepsilon}}}$

The values of these parameters for the X6 NiCrTiMoV 25 are presented in Table 2 [9].

The contact between the billet and all the tools (rigid and thermo-elastic) is modeled with a Coulomb law limited by Tresca (Eq. (6)):

$\|\tau\|=\mu \sigma_{n} \quad$ if $\mu \sigma_{n}<\bar{m} \frac{\sigma_{0}}{\sqrt{3}}$
$\|\tau\|=\bar{m} \frac{\sigma_{0}}{\sqrt{3}} \quad$ if $\mu \sigma_{n} \geq \bar{m} \frac{\sigma_{0}}{\sqrt{3}}$

Table 2

Physical and mechanical properties of X6 CrNiTiMoV 25 billet material [9]

\begin{tabular}{|c|c|c|c|c|c|c|c|c|c|}
\hline$\overline{K_{0}(\mathrm{MPa})}$ & $n$ & $m$ & $\beta(\mathrm{K})$ & $E(\mathrm{GPa})$ & $v$ & $\rho\left(\mathrm{kg} / \mathrm{m}^{3}\right)$ & $C_{p}(\mathrm{~J} / \mathrm{kg} \mathrm{K})$ & $\lambda(\mathrm{W} / \mathrm{m} \mathrm{K})$ & $a\left(\times 10^{6} \mathrm{~mm} / \mathrm{mm}^{\circ} \mathrm{C}\right)$ \\
\hline 297 & 0.019 & 0.126 & 7325 & 483 & 0.35 & 7.3 & 483 & 35 & 23.2 \\
\hline
\end{tabular}




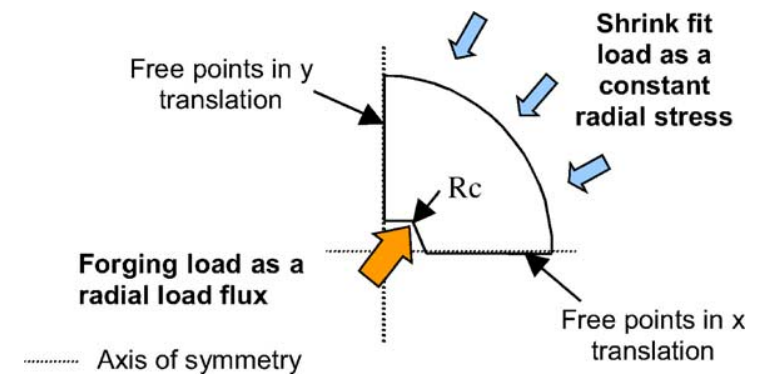

Fig. 7. Die boundary conditions for I-DEAS ${ }^{\circledR}$ numerical simulation.

where $\sigma_{n}$ is the normal stress, $\tau$ the friction shear stress, $\sigma_{0}$ the flow stress, $\mu$ the Coulomb friction coefficient and $\bar{m}$ is the shear friction factor.

The values of $\bar{m}=0.2, \mu=0.4$ were chosen according to previous work [2].

\subsubsection{Thermal boundary conditions}

Two initial uniform billet temperatures are studied: $1100{ }^{\circ} \mathrm{C}$ nominal temperature and $1000^{\circ} \mathrm{C}$. The thermal properties of the billet materials are presented in Table 2 [9]. The thermal exchange coefficient between tools and billet is fixed at $20000 \mathrm{~W} / \mathrm{m}^{2} \mathrm{~K}$ [2].

\subsection{Numerical simulation of die design}

Isothermal numerical simulation is performed under I-DEAS ${ }^{\circledR}$ finite elements software. Taking into account the symmetries of the hexagonal nut, only $1 / 4$ of the cross section of the die is considered (Fig. 7). A thin shell six-node element meshing is used. Non-linear elasto-plastic behavior of the high speed steel material is introduced using a piecewise linear model.
A linear loading or the load increase resulting from Forge ${ }^{\circledR}$ simulation is applied to the inner part of the die. To evaluate the influence of the radius corner, five models are considered, differing only by the radius corner value $(0.05 ; 0.1 ; 0.2 ; 0.5 ; 0.7 \mathrm{~mm})$. The same boundary conditions are applied. The radius values have been selected to be the closest to those found in industry: $0.05 \mathrm{~mm}$ corresponds to the minimum possible machining conditions and $0.5 \mathrm{~mm}$ is the maximum radius allowed by norms and discussed in Section 2.3. To have a look beyond this range, a $0.7 \mathrm{~mm}$ radius is also studied.

To simulate the shrink fitted die, a steady even load is applied on the outer part and three levels are calculated: no shrink fit, 100 and $200 \mathrm{MPa}$.

\section{Results}

\subsection{Axisymetric forging simulation (Forge $2^{\circledR}$ )}

\subsubsection{Temperature and stress distribution in the die}

Fig. 8 shows the temperature gradients in the billet and die, just after the strike of the punch. Very important thermal gradients are noticed on the die surface and the highest temperature $\left(450{ }^{\circ} \mathrm{C}\right)$ is located at the die transition point (point 6 ) which corresponds to point B in Fig. 6. The temperature in the body of the die remains close to room temperature during the whole forging operation.

Fig. 9 shows the radial (a) and circumferential (b) stress distribution at the end of the strike. Maximum stresses are located at the mid-high of the nut (point A of Fig. 6), whereas the transition point (point B) is less constrained. The radial stresses in the die are compressive and their values decrease quickly from the inner side to the center of the die. The stress singularity noticed at the bottom of the die (in contact with

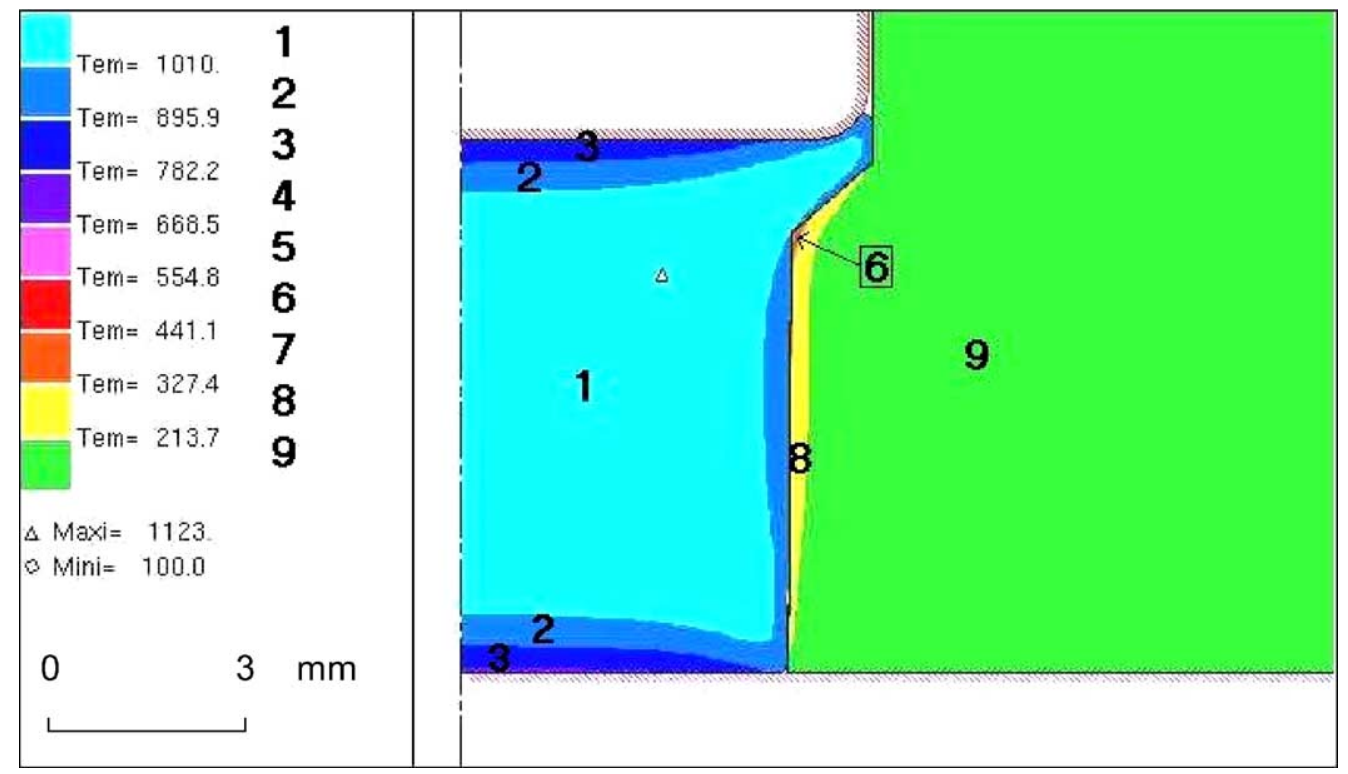

Fig. 8. Temperature in the nut and in the die (scale in $\mathrm{mm}$, temperature in ${ }^{\circ} \mathrm{C}$ ). 


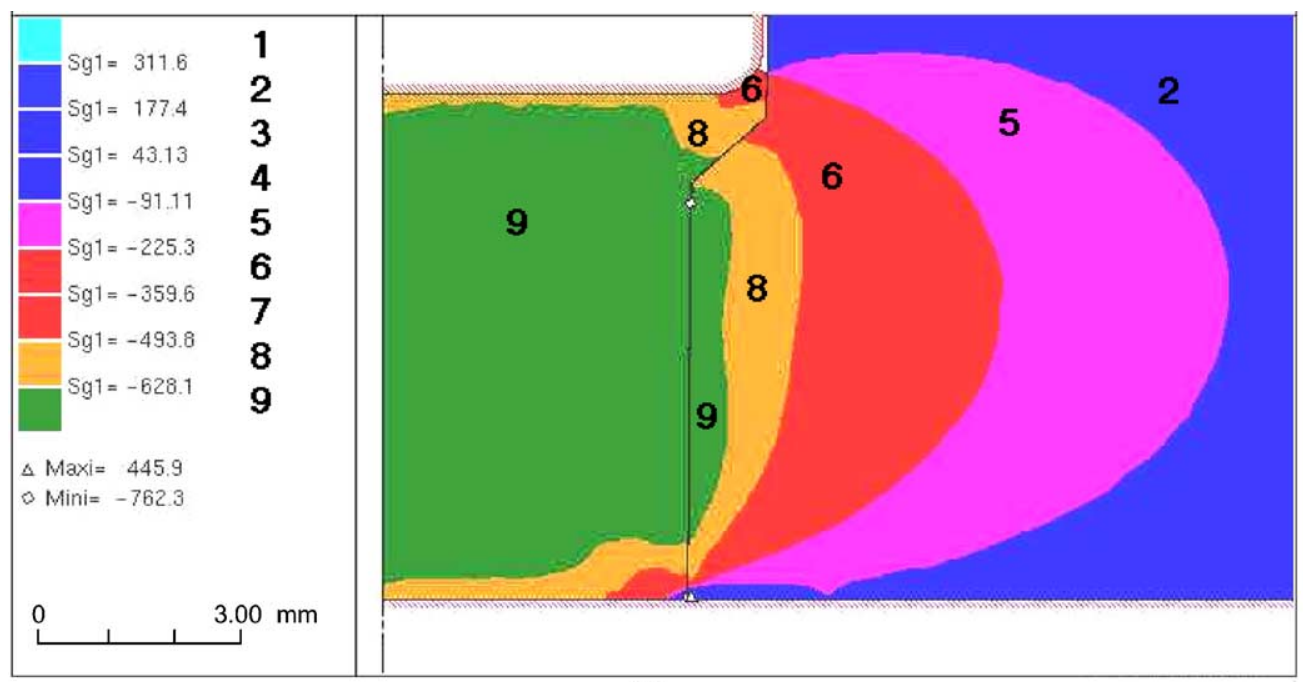

(a)

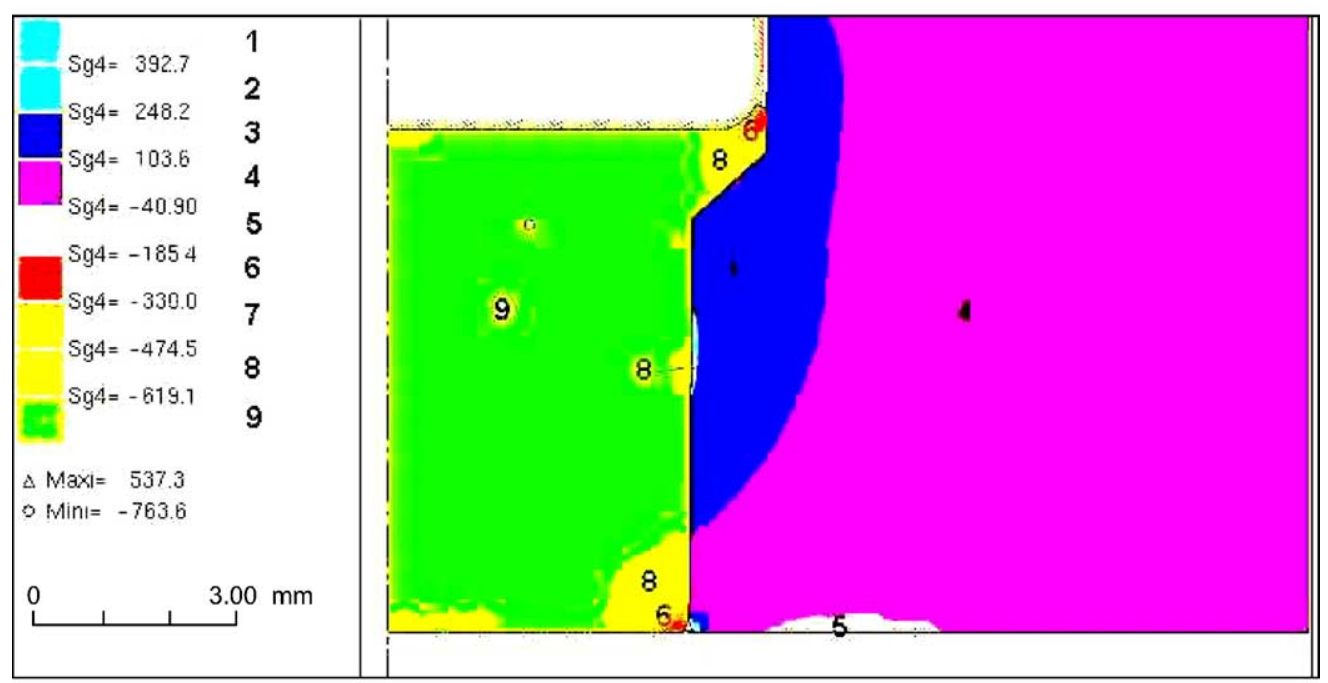

(b)

Fig. 9. (a) Radial stress $\sigma_{\text {rr }}$ in the die (MPa); (b) circumferential stress $\sigma_{\mathrm{t}}$ in the die (MPa).

the lower rigid support (b)) may be related to the no-slip contact condition.

\subsubsection{Forging load evolution overtime}

The load evolution during one forging step is plotted in Fig. 10 for the three billet process parameters studied (see Section 3.1). Compared to nominal conditions (standard length $13 \mathrm{~mm}$, temperature $1100^{\circ} \mathrm{C}$ ), a drop of $100^{\circ} \mathrm{C}$ of the initial billet temperature introduces only a limited increase of the load $(+12 \%)$. In contrary the $1.5 \%$ increase of the initial length induces a dramatic increase of the forging load $(+60 \%)$ and gives evidence of the necessity of a close control of this process parameter.

The evolution of radial loading flux is plotted in Fig. 11 for point location A. It is defined as the load for a unit length (in $\mathrm{MN} / \mathrm{m}$ ) and corresponds to the radial stress at the inner surface of the die. It will be used later as load condition for I-DEAS ${ }^{\circledR}$ combined load simulation.

\subsection{Non-axisymetric simulation of die design influence}

A linear load increase is applied to the different radius corner models (see Fig. 7), to point out the importance of

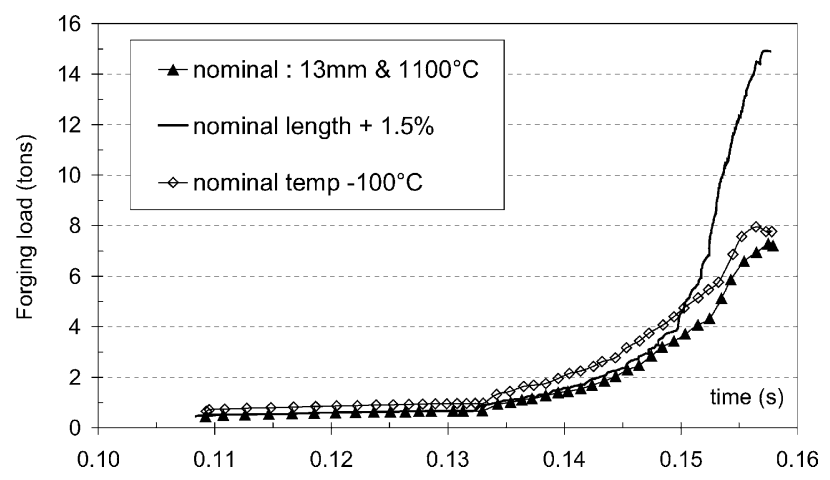

Fig. 10. Forging load evolution in the punch for different billets parameters. 


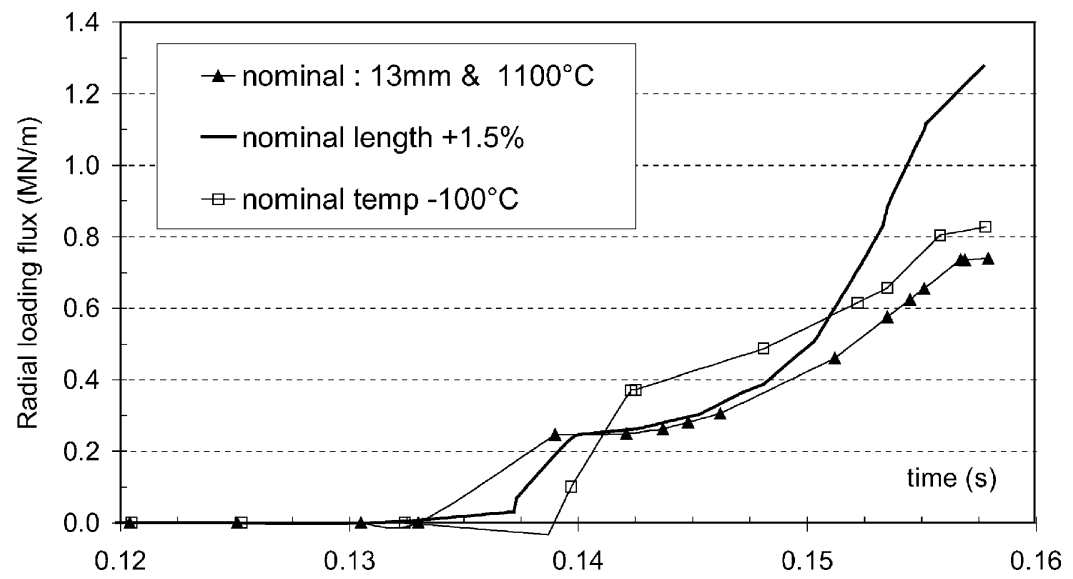

Fig. 11. Radial loading evolution in the die during the forging for different billets parameters (point A).

the radius corner values and the pre-load applied by the shrink-fitting. All simulations are performed at room temperature as the maximum temperature at point $\mathrm{A}$ (where the maximum load is applied) reaches only $200{ }^{\circ} \mathrm{C}$ and as the HSS M2 steel exhibits low property changes at this temperature.

\subsubsection{Radius corner value influence}

As expected, the radius influence is clearly demonstrated, and is shown in Figs. 12 and 13 where the Von Mises plastic equivalent stress is plotted for two radii $(0.05$ and $0.5 \mathrm{~mm})$ under the same radial loading flux $(500 \mathrm{kN} / \mathrm{m})$. In the die with a $0.05 \mathrm{~mm}$ radius, the plastic zone looks like a crack front with the formation of two 'ears' corresponding to a typical configuration of a high stress concentration zone. It may lead to a crack initiation during the first strike and, as the steel has a low toughness, to a rapid propagation during the next hits. In the $0.5 \mathrm{~mm}$ radius die, the strain is well distributed along the radius; there is a smooth stress con- centration. The stress level is significantly reduced, $-30 \%$ in this particular loading case.

Taking into account the simulated radius values of 0.1 , 0.2 and $0.7 \mathrm{~mm}$, Fig. 14 shows the evolution of the Von Mises equivalent stress as the level of the radial loading flux increases. The non-linearity of these curves is related to the non-linear elasto-plastic behavior of the material. The stress decreases while the radius increases, up to a limit value of $0.5 \mathrm{~mm}$, over which the radius seems to have less influence. On this plot are also reported the yield stress and rupture stress of the die material at $20^{\circ} \mathrm{C}$. It can be seen that these stresses are largely over-crossed in the die.

\subsubsection{Shrink fit influence}

Fig. 15 shows the effects of the application of a shrink fit pre-load on the outer part of the die (corner radius $0.5 \mathrm{~mm}$ ). The stress increases with the forging load, but, if a shrink fit is applied, the equivalent Von Mises stress first decreases. Indeed, the tensile stresses first compensate the compressive

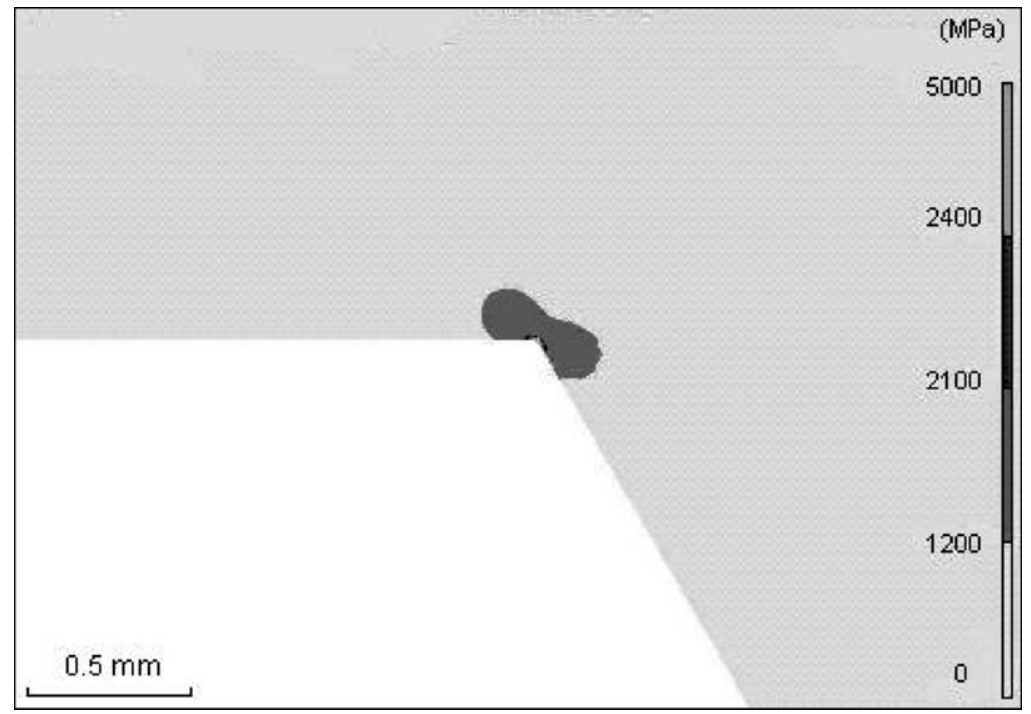

Fig. 12. Von Mises equivalent stress in die with a $0.05 \mathrm{~mm}$ radius. Radial load: $500 \mathrm{kN} / \mathrm{m}$. 


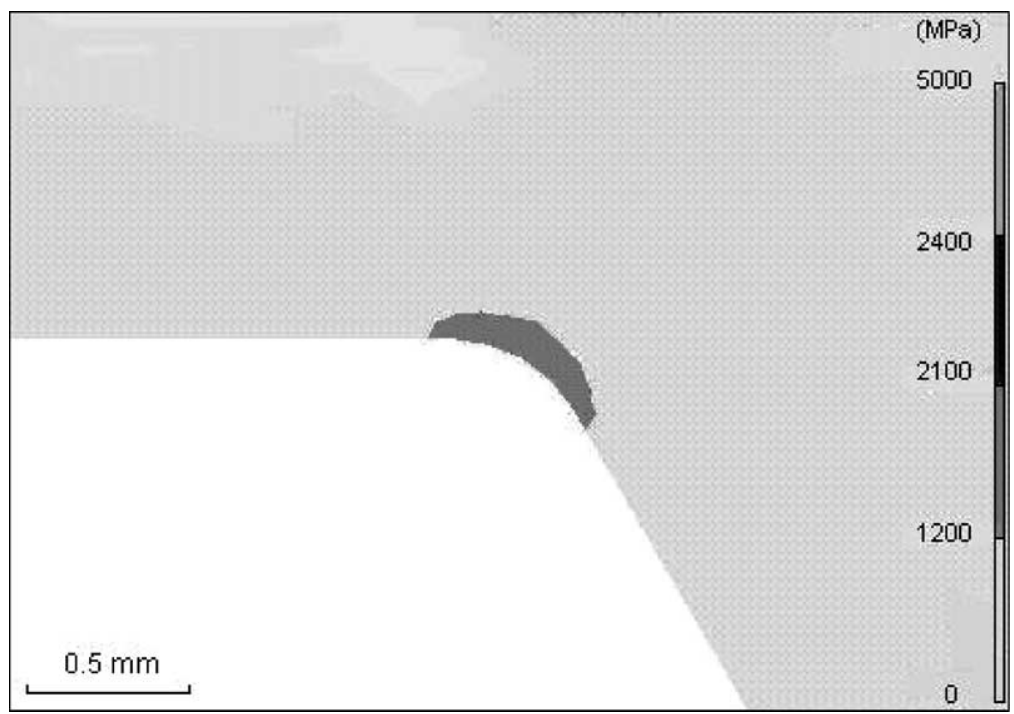

Fig. 13. Von Mises equivalent stress in die with a $0.5 \mathrm{~mm}$ radius. Radial load: $500 \mathrm{kN} / \mathrm{m}$.

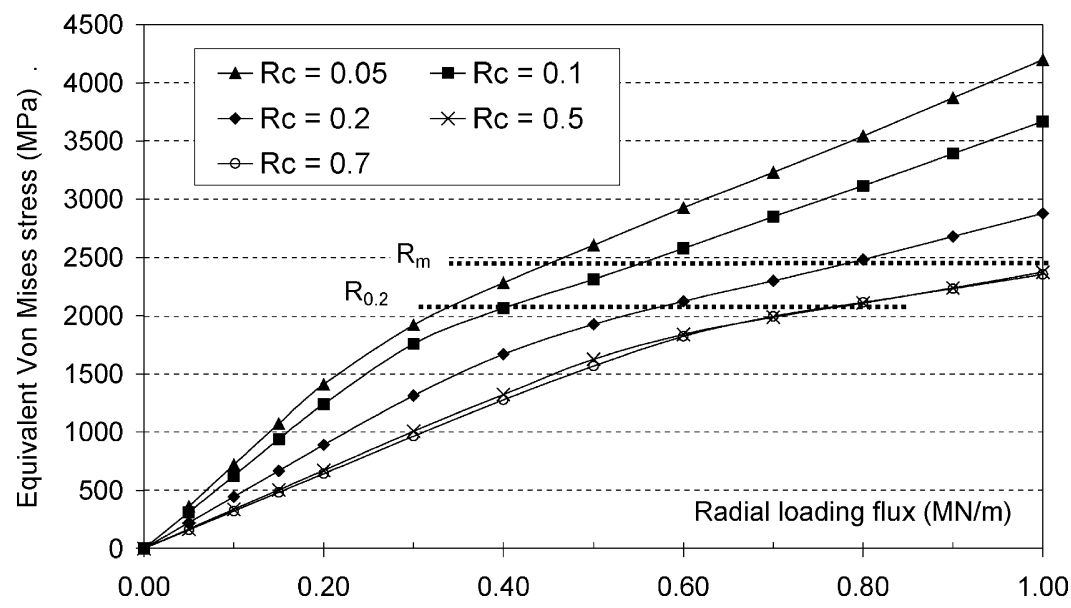

Fig. 14. Evolution of Von Mises stress with radial loading for different die radii.

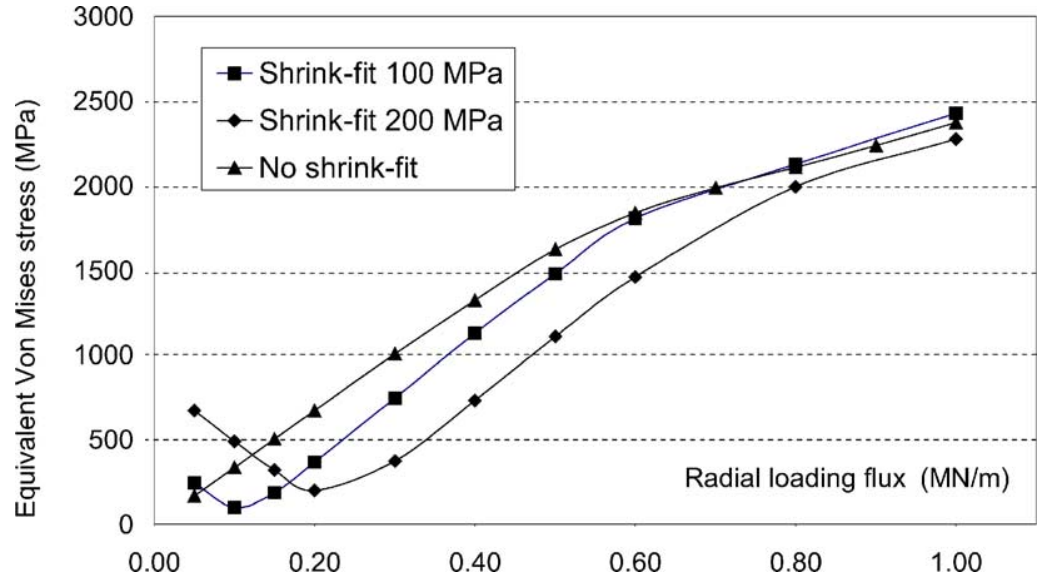

Fig. 15. Von Mises equivalent stress evolution in the die for different radial loads and for different pre-stressed conditions. 


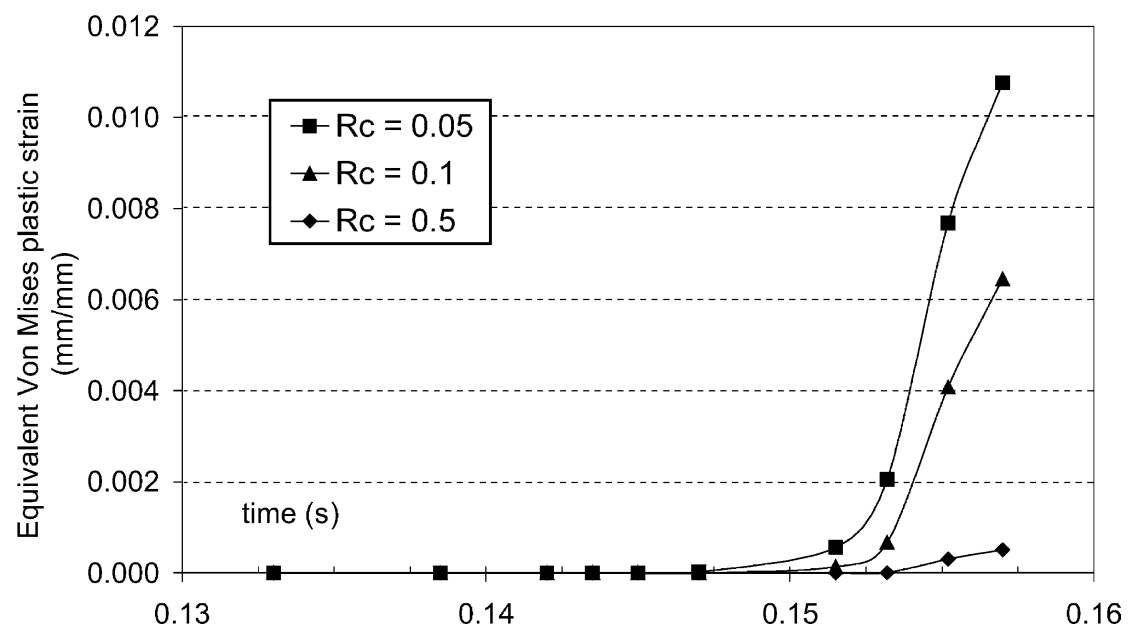

Fig. 16. Evolution of Von Mises plastic strain during the forging for different radii.

ones introduced by the shrink fitting; this effect is equivalent to delay the loading and so the entrance into the plastic zone of the material. Below the yield strength, the shrink fitted curves have the same slopes, beyond this value, the influence of shrinking is not as important as die material undergoes important plastic straining. In the elastic zone, the up to $600 \mathrm{MPa}$ stress difference between 200 and $0 \mathrm{MPa}$ shrink fit level shows the great importance of the selection and the control of this parameter.

\subsection{Combined simulation}

In the combined simulation, the radial loading flux history of Fig. 11 (for the nominal conditions $13 \mathrm{~mm}$ length and $1100{ }^{\circ} \mathrm{C}$ ) is applied to a $200 \mathrm{MPa}$ shrink fitted die. Fig. 16 shows the evolution of the equivalent Von Mises plastic strain versus time for three different radii: 0.05, 0.1 and $0.5 \mathrm{~mm}$. For the highest level of the radius, plastic strain is small and remains under the conventional limit of elasticity (corresponding to a $2 \times 10^{-3}$ plastic strain). Knowing that the maximum plastic strain in tensile rupture testing of the die material at $450{ }^{\circ} \mathrm{C}$ is close to $1.2 \times 10^{-2}$ [10], $0.1 \mathrm{~mm}$ and especially $0.05 \mathrm{~mm}$ radius values may produce rapid crack initiation during the first nut production. Moreover, when radius value is low, a little variation $(0.05-0.1)$ introduces an important modification of the plastic strain.

\section{Discussion and service life}

\subsection{Discussion}

All these results show the influences of combined design and process factors. One of the most important seems to be the radius in the hexagonal head of the nut. The use of a $0.5 \mathrm{~mm}$ radius seems to be the best compromise between the norms specifications and the stress distribution in the die. As a matter of fact, it allows to stay under the conventional yield strength, whereas for lower radii, the ultimate strength would be overcome. The use of high hardness steels (and in consequence low toughness steels) to form the high mechanical property billets promotes the crack propagation after initiation on the inner part of the die.

Another important design factor is shrink fit. It enables to reduce the equivalent Von Mises stress in the tools and to delay the failure initiation. Nevertheless, its efficiency is restricted to the elastic domain and seems to vanish when the die undergoes important plastic straining.

At least, this study shows also the influence of the billet initial length, for which an increase of $1.5 \%$ (corresponding to the general accuracy of the cutting machine) multiplies the mechanical loads on the die by a factor of 2 .

\subsection{Service life prediction}

An estimate of the impact of these finite element calculations on fatigue life may be performed using the universal slope method proposed by Manson [11]. This method allows to link service life and total strain amplitude, whatever the material under consideration. The advantages of the method are the limited number of material properties needed and the fact they can be defined thanks to a simple tensile test. He derives the relation below:

$\Delta \varepsilon_{\text {total }}=M\left(N_{\mathrm{f}}\right)^{Z}+\frac{G}{E}\left(N_{\mathrm{f}}\right)^{\gamma}$

where $N_{\mathrm{f}}$ is the number of cycles to failure, $E$ the elastic modulus of the material, $Z$ and $\gamma$ are constant parameters (respectively, -0.6 and -0.12 ) and $M$ and $G$ are defined by the equations: $M=-\ln \left(1-R_{\mathrm{a}}\right)^{0.6}, R_{\mathrm{a}}$ is the reduction in area; $G=3.5 \sigma_{\mathrm{u}}, \sigma_{\mathrm{u}}$ is the ultimate tensile strength; $E$, $R_{\mathrm{a}}$ and $\sigma_{\mathrm{u}}$ for the HSS M2 steel are, respectively, $210 \mathrm{GPa}$, 0.024 and $2400 \mathrm{MPa}$.

Fig. 17 and Table 3 report an estimate of the service lives, for different radius corner values. For the lower radius corner value, the service life is very low, 260 cycles. For $0.2 \mathrm{~mm}$, the number of cycles to failure increases to 5200 cycles; it 


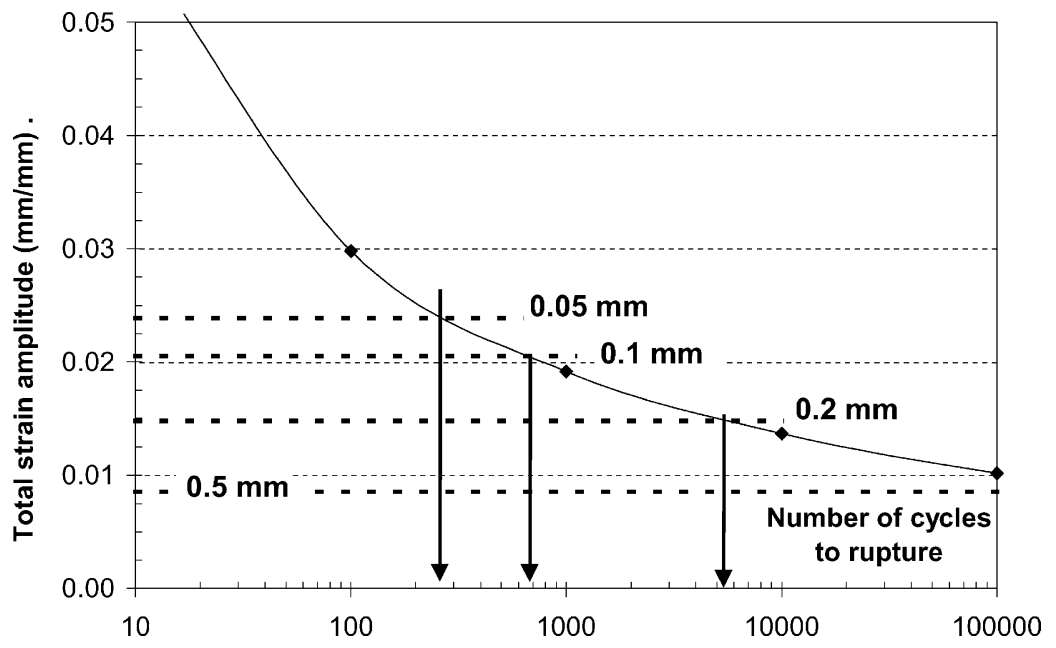

Fig. 17. Universal slope diagram for HSS M2 steel and life time of dies with respect to corner radius.

reaches more than $10^{5}$ cycles for $0.5 \mathrm{~mm}$. This evaluation does not take into account the problems like wear and all the other possible causes of failure, but it gives a good way to compare and to quantify the radius corner influence.

\subsection{Industrial verification}

Verification of simulation results are performed on dies with the 0.3 and $0.5 \mathrm{~mm}$ radius. The nominal die life in the $0.05 \mathrm{~mm}$ radius configuration is between 50 and 200 pieces. These data are coherent with the theoretical evaluation of service life done in the previous paragraph. Following observations have been performed with the new die designs.

First, the introduction of design with 0.3 and $0.5 \mathrm{~mm}$ radius induces no extra costs during the machining. Second, the nuts have good dimensions according to the specifications and norms, and even better: as a matter of fact, nuts with a low radius are sensitive to thermal cracking during quenching, due to the high stress concentration induced by high temperature gradients in the corners. When radius is increased, these problems become less important. Observation of the cross-section of the as forged nuts shows that the radii are 0.4 and $0.6 \mathrm{~mm}$ with respectively, the 0.3 and $0.5 \mathrm{~mm}$ dies.

Second, filling of the bottom of the dies with the old designs was often difficult and requires higher forging loads. Now there is a radius and there is no more a need to increase

\section{Table 3}

Estimated dies service life, depending on the radius corner of the die $\left(R_{\mathrm{c}}\right)$, for a $200 \mathrm{MPa}$ shrink fit

\begin{tabular}{llc}
\hline$R_{\mathrm{c}}(\mathrm{mm})$ & $\Delta \varepsilon_{\text {total }}(\mathrm{mm} / \mathrm{mm})$ & Service life \\
\hline 0.05 & $2.387 \times 10^{-2}$ & 260 \\
0.1 & $2.052 \times 10^{-2}$ & 700 \\
0.2 & $1.448 \times 10^{-2}$ & 5200 \\
0.5 & $8.55 \times 10^{-3}$ & $>10^{5}$ \\
\hline
\end{tabular}

the loads to produce nuts without defects.

At least, no rupture nor crack initiation were observed during production after 1000 nuts. Tests are continuing.

\section{Conclusion}

Increase of nut forging die life time was investigated with a combined forging process and thermo-mechanical die simulation. It was in particular shown that:

- a closer control of the initial billet length is more important than a control of billet forging temperature. A $1.5 \%$ error (i.e. $0.2 \mathrm{~mm}$ in this case) multiplies the forging load and the radial loading flux on the die by a factor of 2 ;

- an increase of the corner radius of the die from 0.05 to 0.5 (which remains compatible with nut norms) may increase the life time by a factor greater than 100 ;

- a well controlled shrink fitting of the die has a major effect on stress level. This effect vanishes nevertheless, when high plastic strains are reached, i.e. when die design is not optimized.

Modification of the die design have been introduced in industry and results show a significant increase in die life time as expected.

\section{Acknowledgements}

The authors would like to acknowledge the company LISI Aerospace for its financial and technical support to this study.

\section{References}

[1] J. Walters, S. Kurtz, W.-T. Wu, J. Tang, The 'state of the art' in cold forging simulation, J. Mater. Process. Technol. 71 (1997) 64-70. 
[2] O. Brucelle, G. Bernhart, Methodology for service life increase of hot forging tools, J. Mater. Process. Technol. 87 (1999) 237-246.

[3] O. Sandberg, B. Klarenford, H. Lindow, A new hot work tool steel with improved properties, tool steel in the next century, in: Proceedings of the Fifth International Conference on Tooling, University of Leoben, Austria, 29 September 1999.

[4] B. Chicco, G.L. Powell, G. Hefrfurth, E. Summerville, Failure in Hot Forging Dies, Materials Australia, September/October 1997, pp. 24-26.

[5] G. Frediksson, J. Bergström, S. Hogmark, Crack growth in cold work tool steels-influence of surface condition, microstructure and hardness, tools steels in the next century, in: Proceedings of the Fifth
International Conference on Tooling, University of Leoben, Austria, 29 September 1999.

[6] H.-J. Kim, J.F. Wallace, Effect of EDM and its mitigation by surface modification on thermal fatigue properties, Surf. Eng. 10 (1) (1994) $56-64$.

[7] T. Bobke, H. Luig, Causes de Défaillances des Outils d'Estampage, University of Hanover, 1989 (translation).

[8] Norms ISO 4759, I and II. Tolerances for Fasteners, 1978.

[9] Technical Data Base, Blanc LISI Aerospace.

[10] G. Bernhart, unpublished test results.

[11] S.S. Manson, Thermal Stress and Low Cycle Fatigue, McGraw-Hill, New York, 1966. 